\title{
UCD Guerrilla Tactics
}

\section{A Strategy for Implementation of UCD in Sweden's Military Defense Organizations}

\author{
Elina Eriksson ${ }^{1}$ and Anna Swartling ${ }^{2}$ \\ ${ }^{1}$ Media Technology and Interaction Design - MID, KTH - Royal Institute of Technology, \\ SE-100 44 Stockholm, Sweden \\ elina@kth.se \\ ${ }^{2}$ Scania CV AB, SE-151 87 Södertälje, Sweden \\ anna.swartling@scania.com
}

\begin{abstract}
The problem of how to implement user-centred design (UCD) is well established as a research topic within HCI. Yet there are unresolved issues in order for UCD to actually be used in practice. This paper will present a case study within Sweden's military defense organizations, concerning the introduction of UCD. The overarching goal of the research was to bridge the gap between work practices and systems development; focusing the efforts on introducing usability work in the procurement process. We concluded early on that we needed to develop and formulate an approach that is probably common in practice but not described or used in research. We call this strategy UCD guerrilla tactics, which entails to do the unexpected, to work pragmatically with change, and to use user centred methods to introduce UCD. Our main target group was future users and procurers of UCD methods. We aimed at demonstrating and involving them in the work through user centred activities. The tactics is also a reflexive and flexible approach based on continuous evaluation of what is feasible and potentially gives the largest outcome. This paper describes the guerrilla tactics, how it was applied in a case study and factors that should be considered when using it.
\end{abstract}

Keywords: User-centred design, procurement, usability, organizational change, case study, work practice.

\section{Introduction}

User-centred design (UCD) is well established within the HCI research field. It can be perceived as an umbrella concept for a variety of methods, techniques, processes and approaches. Often when UCD is mentioned it is not used for a particular process, but refers to a situation in which methods with a focus on users have been used. For example in a study that surveyed people attending CHI2000 [1], several methods were included: field studies (including contextual inquiry), user requirements analysis, iterative design, usability evaluation, task analysis, focus groups, formal heuristic evaluations, user interviews, prototype without user testing, surveys, informal expert 
reviews, card sorting, and participatory design. There are also influential attempts to define it more specifically e.g. [2-4]. But even though UCD is established within the HCI-field, it is still difficult to make UCD work in practice [5-7]. There are numerous studies presenting cases where UCD has been used or been introduced in organizations [8-10]. However, there exists no silver bullet, in the sense of a context free and all encompassing way to do the introduction [11]. Several attempts seem to use a subtle approach, like Kujala's Trojan Horse [12] where the field study method was simplified and the results presented in a familiar form.

UCD is by tradition often included when there is a concrete systems development project [13]. But there are many activities concerning work practices and requirement formulation taking place before the start of a project, which means that UCD activities might come into play too late. There is a need to bridge the gap in the procurement process (sometimes referred to as acquisition) between work practice, organizational development and systems development $[14,15]$. Moreover there is a lack of techniques and methods supporting procurers to incorporate UCD and usability into their processes $[16,17]$.

Furthermore, our focus is not only to include UCD in individual projects but to establish a user-centred attitude within the organization [4] with the aim of changing the overall work processes for procurement and development of IT-systems. But how can that be achieved? If the traditional way of introducing UCD is failing, i.e. introducing it in the formal system development process, might there be another way?

User-centred guerrilla tactics is not a concept commonly used within HCI research, though similar terms are frequently used in industry to describe how to introduce usability within organizations. There is no clear common definition, more than that it comprises using a subtle approach and sneaking usability into the systems development process. Perhaps the most cited use is Jacob Nielsen's text on "Guerilla HCI" in which he advocates for gradually introducing usability by "... starting with the bare minimum and gradually progressing to a more refined lifecycle approach" [18].

Based on the second author's previous research in Sweden's military defense organizations [19] we aimed at developing the early phases of systems development: the procurement process. We developed a strategy especially focusing on what can be done when the resources are scarce. We call this strategy UCD guerrilla tactics.

The UCD guerrilla tactics is a pragmatic approach focusing on what is feasible and potentially gives the largest outcome with few resources. This meant for example in our case, targeting change projects, key people and being open to unconventional activities. To succeed with this, we continuously reflected and evaluated whether we were successful or not with our chosen activities. If not, we adapted or changed what we were doing. When choosing activities we based our actions on the context and the situations that were available.

Furthermore, the strategy initiates a change by using user centred methods for introducing $\boldsymbol{U C D}$, i.e. treating the respondents as both participants and recipients. We did this by involving them in user centred activities but also through demonstrations of how usability methods could be used in the procurement process.

To conclude, the purpose of this paper is to present an approach for implementing UCD. We do this by describing our case study within Sweden's military defense 
organizations. The purpose of this paper is not to describe a detailed work analysis but rather to analyze prerequisites for UCD in general where work analysis is a part of the methodology. This paper does not elaborate on the result in terms of the degree of UCD actually implemented in the organizations. Rather, we reflect on the approach chosen and the consequences thereof.

\section{Research Settings}

Sweden's military defense setting comprises several organizations where two of the most prominent are the Swedish Armed Forces (SwAF) and the Swedish Defense Materiel Administration (FMV). SwAF is the authority that carries out international missions, protects the integrity of Swedish borders and supports the society in major crisis. FMV is Sweden's oldest civil governmental agency and its main task has remained the same over time: to strengthen the operational capability of the defense system by acquiring materiel (i.e. the equipment and supplies of a military force) in a cost-effective way. In most cases, FMV works as a middleman between the armed forces and the system developers.

SwAF procures IT systems from FMV, which in turn executes the procurements through contracts with industry. FMV does not usually do any development on its own; its responsibility is to initiate and supervise contracts with industry based on the procurements from SwAF. For this work, FMVs tradition is to employ engineers who analyze requirements and manage projects. Many formal processes have been defined and the procedures for handling procurement and systems development are extensive.

The individual units within the armed forces are the end-users of the IT systems; they inform the people in charge of procurement at SwAF headquarter (HQ) of the needs that arise during the evaluation and use of the systems. They are also in close contact with FMV as it evaluates both old and new equipment. Finally, during implementation FMV often engage them to evaluate the system. The units can also have direct contact with industry if they experience problems with an existing system and report them to the companies in charge of maintenance and support.

\subsection{Research Method}

The case study presented in this paper was conducted in Sweden's military defense organizations from the autumn of 2009 to the spring of 2011. The procurer of the research project was FMV. Several other research collaborations with FMV had preceded this project with the main aim of understanding usability issues in relation to the procurement process [19]. However the focus of this project was somewhat different. The project manager at FMV wished that our research should be more aimed at making a change rather than just reporting the current state. Thus the over-arching aim of the project was to introduce a higher focus on user-centeredness in the early phases of the requirement and procurement processes at SwAF.

The empirical material was collected through semi-structured interviews with the procurer, IS strategists, enterprise architects, development personnel in units and 
usability experts. We have also collected data through workshops with the same kind of participants. All respondents were given information about research ethics such as confidentiality and anonymity. The workshops and the interviews were in all cases except one audio recorded and transcribed. Furthermore, we have at all times been using research diaries, in which we have written down thoughts, conversations etc. as well as more structured field notes when doing participant observations. Moreover we have reviewed an extensive amount of written documents and presentations from the organizations. The overall data analysis has been iterative and we have revisited the material many times during the course of the project.

\section{Result: Tactics in Practice}

The core aspect of the strategy is to shift focus from the end-users of IT-systems to the users of the UCD methods or the recipients of the result such as procurers, strategists, project managers or system developers. Furthermore, it is about using classic participatory methods. The aim is to design a version of UCD that can work in a specific organization and to achieve that through collaboration with the people affected by the new work practice. Here we will describe how we tried to achieve that.

\subsection{Reflexive Pragmatism}

In comparison to traditional UCD introduction, which in general have a set agenda, we continuously reflected on how we could adjust our approach so that we could achieve the largest outcome. When we encountered problems we regrouped and found new activities that we thought could be more feasible.

From the outset we considered action research [20] as a suitable methodology for the project. Albeit in the initial discussions, it became clear that this was not possible due to politics within the defense organizations (the politics and the organizational structures are interesting in this case, see Debriefing and Discussion). This was one of our first situations in which we had to adjust to the situation given to us. We discussed the issue and pragmatically adapted our approach. In consequence, we decided to work as an action research project, but without actually talking about it as such. We still had a dual aim of both solving a problem in practice as well as a research problem [21], with the drawback of not being able to collaborate to the extent optimal for an action research project.

Within Sweden's military defense organizations several terms were used that relates to usability and usability work, some examples are Human Factors (HF), HumanComputer Interaction (HCI), and Human-Machine Interaction (HMI). The usage of this terminology was not clear, as in this quote from one of the respondents: "We usually say Human Factors, and I don't know if people honestly know what it means, or if people just pretend that they do. [...] We use it and people nod and smile but perhaps they just don't understand what we do." Furthermore, in the previous studies of Sweden's military defense organizations [19], the second author had observed that the meaning many respondents gave usability differed from the one the HCI community 
gives it. Therefore, in line with our pragmatic approach, we decided to start using a somewhat new terminology in this research project, primarily Human-centeredness (HC).

\subsection{Pilot Project}

At the start of the research project, it was not clear how we were supposed to accomplish the change in work practice that the project strived for. SwAF is a large organization and we concluded that aiming for changing it in its entirety was not an option. We decided instead, based on our pragmatic approach, to find an on-going development project where we could have an impact. We found a project with the aim to implement enterprise architecture (EA) in SwAF (here named the EA project). They were working on future rules for how SwAF should be described, a local EA framework, and a methodology for using architecture within the procurement process. We hypothesized that we could gain something from introducing UCD while the organization was changing its work practice anyway.

\subsection{UCD with UCD}

One major part of the tactics was to initiate change, that is, introducing UCD, through user centred methods and a user centred attitude. With this we mean treating the respondents as both participants and recipients. Or expressed differently, we considered the possible users of the usability methods and activities as exactly that: users. Hence, we involved them in user centred activities, but also in demonstrations of how usability methods could be used in the procurement process.

We wanted to introduce both classic UCD methods as well as new methods that we thought might fit this particular organization and these particular participants; we chose to explore case study [22], personas [23], scenarios [23], conceptual sketching [24], coaching [25], and Cynefin inspired methods [26]. Several other activities were also conducted. For example, we commented on and proofread several relevant documents produced by others. Furthermore, the first author interviewed usability professionals within SwAF and FMV.

The strategy resulted in us working with UCD on many different levels: 1) integration of UCD in new formal structures; 2) using user centred methods when working with the project to define and implement new formal structures (with project members and end-users of the formal structures); 3) using UCD methods with end-users of technical artifacts related to the new formal structures.

\section{Debriefing and Discussion}

We will here reflect on our application of the UCD guerrilla tactics in relation to the empirical data. By analyzing and describing the barriers it is possible to get a deeper understanding of the problems and the potentials of this strategy but also the introduction of UCD in general. 


\subsection{Usability Competence}

FMV had a declining number of usability professionals in the years preceding this research project, with a maximum of ten usability professionals among its $1500 \mathrm{em}$ ployees. There were also a non-active network of people interested in, and working with usability issues. Since the usability professionals were few they could not participate in many projects and had little time for policy creation or strategic usability work. At SwAF there was a great lack of usability professionals and usability competence. In many of our interviews, with stakeholders from both SwAF and FMV, the responsibility for including usability in procurement was put on SwAF but it was also acknowledged that there is nobody there to take on this responsibility. There were some that had training in systems theory where Human Factors had been a part, but according to our respondents they were scarce and dispersed and mainly working with other things.

We tried to engage the usability professionals and succeeded to some extent. They participated in several workshops and one of them acted as a co-facilitator in a couple of workshops with end-users. But in the end, we researchers were the main actors and the majority of activities were done by us alone. So in this respect, the UCD guerilla tactics was not enough. We needed more support and engagement from the organization than was possible.

The lack of usability professionals had serious implications for the introduction of UCD primarily as we had no one to collaborate with. Research show that usability practitioners are important [27], not only for collaboration, but also for ensuring a sustainable change in the organization. Someone have to continue to work with these issues after the research project has ended.

\subsection{Organizational Structures and Politics}

The division of responsibility was sharply divided between the defense organizations; regulated by formal documents from the government and by historical aspects. SwAF is the only authority in Sweden engaged in armed combat, but they were not allowed to perform any kind of development of artifacts supporting combat. The situation was similar for FMV. In general, they were not supposed to develop any artifacts for combat themselves; instead they acted as a support organization for SwAF directing procurements to industry. The interaction between the organizations were settled in collaboration contracts, but also deduced to routines and established practice. Several of our respondents expressed that working with user involvement was difficult for several reasons. One was the distance between users and the development project. When involving users, it was FMV who formally requested resources from HQ. It was not possible for the units or HQ to demand user involvement in a development project. Instead, if they wished that end-users should be involved they had to ask FMV to include it in their offer to SwAF. Sometimes FMV requested user groups and user representatives but never more elaborate and efficient ways of UCD. In some cases, different stakeholders bypassed the routines and through personal contacts made sure that end-users were included in development projects or that personnel from FMV were included in the early requirements process. 
SwAF was a very hierarchical organization. For example, the EA project was explicitly told not to contact people working at HQ or in the units. Politics was always present during the research project. At one time, after most project members had been asked to leave from a meeting with the procurer of the EA project, one respondent explained: "This is about $P-O-W-E-R$."

Our research interest was to bridge the gap between work practice and systems development within Sweden's military defense organizations. Our starting point was in FMV within a research project. This made sense in some regard, since FMV did work with development and procurement of materiel and there existed at least some usability professionals. However, in order to introduce a higher focus on usability in the earliest phases of systems development much of our attention should be directed at SwAF. With all the organizational and political hindrances mentioned above, the starting point was perhaps not the best for this project. But not all research projects start off in the right situation, e.g. [27]. However, it is difficult to see what would have been better with an enterprise as big as Sweden's military defense. For us, there was no other choice at this point in time. As a result, we used the guerrilla tactics, working pragmatically with the possibilities given.

More explicit support from higher management could have been beneficial in this [4]. We tried to address this issue both before and during the project. For example, we approached and collaborated with people who either worked closely with higher management at SwAF or was part of it. We succeeded to some extent as human centeredness was included as a core premise in the project assignment for the EA project but it was far from enough.

\subsection{Terminology}

As described above, we explicitly decided to stop using "user centred" in favor of "human centred". We could immediately observe that this label generated more relevant discussions within the organizations. It also resulted in the integration of human centeredness in the procurer's project directive for the EA project.

\subsection{Following a Project}

We engaged in many different UCD related activities with the EA project. In the beginning the most central project members were interviewed and we constructed a plan for UCD activities. We also participated in project meetings and analyzed existing HCI related work to see if parts could be applied to the EA approach. Moreover, we did presentations of HCI methodology and a workshop with the aim of conceptualizing what user-centeredness could be and the expectations of the project members. The first author also performed an interview study with one of the end-user groups of the EA methodology; officers working in the early phases of procurement.

In this context, we encountered yet another taboo situation: due to politics we were not allowed to use the word "coaching". But our continuous presence in the EA project led to several informal coaching situations which we took advantage of. We were also asked to explain issues concerning usability or to come with suggestions for 
further work. At one point the EA project were writing a RFI (Request for Information), a pre-acquisition document and we were asked to evaluate it. This led to usability requirements (both in terms of functional requirements and requirements for a usercentred developmental process) were added in the document.

At the very end of the research initiative, the EA project was given new directions aiming primarily to formulate a change plan for SwAF as well as deliver a prototype of a technical portal, a system for accessing and working with the architecture framework. We identified this as an opportunity to exemplify a more complete UCD process and it was decided that we were to make personas, scenarios of future work and conceptual sketches of the prototype. The work with the personas are described in [28].

Our main goal with follow the EA project was to promote our ideas and change the practice. There are several advantages to working with an existing project; for example, one gets an organizational context to work in. However we also got associated with this particular project, and when it fell out of grace it was reflected on our work. Furthermore in our case we had to balance the needs from the EA project with the demands from the research project. The deliverables in the two projects did not always overlap, and financially the research project had precedence. Another problem with following a project closely is the detachment needed when doing research. Responsibility concerning for example confidentiality and anonymity did not always match the interests of the project we followed. This is a problem described by Walsham [29]: even though you withhold the names of the respondents there is always a risk that the receiver of the information makes an informed guess. This was accentuated at times when we as researchers got information that would benefit the EA project, but due to research ethics could not be shared with them. To what extent should a researcher act as a go-between in organizational politics?

Unfortunately SwAF terminated the EA project prematurely, and the potential for an introduction through that particular change project was lost. In line with the UCD guerilla tactics we would have investigated other possibilities to direct our attention to, but the research project also ended at about the same time.

\subsection{Working with UCD Methods}

The most successful method we used was the persona method, both in terms of engaging end-users in discussions of future work practice and technology use and as a communication tool with the strategic group planning the future work. The scenarios and conceptual sketches developed were also well received by the strategic group that was planning to develop a prototype.

In the previous studies of Sweden's military defense organizations [19], the second author had concluded that it could be a good idea to try out other methods than traditional UCD methods when working with strategic personnel. In this effort we decided to try out a framework which included a whole battery of workshop methods and was based on similar theoretic premises as we have in our research. This framework is called Cynefin [26]. One interesting event was a breakdown of a workshop held with the strategic group in the beginning of the persona activities. In the workshop we used narratives of the end-users work situation (inspired by the Cynefin framework [26]). 
From these narratives, the workshop participants were asked to specify characters (someone doing something) and activities (what is getting done) on sticky notes. Then they were asked to relate these to each other, with the focus of understanding the concrete work of the officers in the procurement process. The participants in the workshop protested to the open-ended situation and the language we used in the workshop. We usability researchers used the words "concrete" and "details" in order to direct the participants towards describing the actual people doing the work, and the actual work they were doing. The participants, who were all focused on EA and strategic planning, used the same words, but with the meaning of doing more detailed flow charts and UML diagrams on roles and processes which we consider a generalized way of describing work.

We also used the Cynefin method for alternative history [26]. It was used in the beginning of the project in order to gain a better understanding of the participants' views on UCD and their expectations for the project. Several obstacles for introducing UCD were visualized and in fact, many of them turned out to be problems during the course of the research project.

The least successful method was a traditional case study with interviews followed by a written report of the findings. Even though we could later use the interview data for the work with personas and scenarios, the recipients did not see any use of the report. This might be related to the dominating way of communicating findings and ideas within SwAF and FMV being presentation slides, which is a less dense format.

It was interesting that within these organizations that emphasize rationality and facts, the report as a method, which often is perceived as "factual", was not successful while the persona method which explicitly is described as subjective was more successful.

For us, the main point in practicing these UCD methods was to demonstrate different possibilities for SwAF in general and the project members specifically. But when it came to the report as a method it was not perceived as an example. Instead the interviews showed that several people saw it as a failure for human centeredness in general and did not see the point of it at all. We often have noticed that negative results are generalized while positive results are constructed as unique successes. It was therefore important for us to continue striving for a multitude of different examples and methods so that the unique in the end would be perceived as a range of possibilities instead of unique instances.

\subsection{Multitudes of Levels}

During our research we have been grappling with an elusive meta-level. The supreme goal of our research was that the end-users, the soldiers, should have usable technical artifacts, but we were not working with the development of these artifacts. Our focus was rather the people developing these artifacts and our mission was to develop the work practice and the methods for them: the users of our methods. We were trying to work in a user-centred manner with these users in focus, to make them work more user-centred with their users in focus. This notion was not always easy to convey.

An example was a recurring discussion we had with representatives from FMV. They argued that our focus was wrong and wanted us to define what benefit the end-users 
would get from our research. We tried to explain that the end-users would get a benefit in the end, but that our research result was a step in the right direction rather than contributing to technical artifacts in that particular moment in time.

Many of the activities we did were directed towards getting research data or information for the EA project. But at the same time offering an example for how they could work in a user-centred manner. Difficulties arose when trying to report back to the EA project. What should we emphasize: the results from the UCD activities, i.e. the information the EA project were mostly interested in, or the UCD methods themselves which was something we wanted them to include in their visions for future systems development?

We do believe that UCD with UCD can be a successful way of introducing UCD but it was not clear to us how difficult it would be for both us and our collaborators to understand all the levels that this implies. In future work, we would emphasize this to a much greater extent than we did in this case study.

\section{Conclusion}

We have explored a pragmatic reflexive user centred approach to the introduction of UCD, which we call UCD guerrilla tactics. It was used as a way to initiate a change process within a large complex organization by the use of very small resources. More intuitive versions of this strategy are probably applied in industry on a daily basis but it is seldom used (or at least not acknowledged) in research. We wanted to explore it in a structured way in order to analyze its potentials. It is also a contribution to those who focus on HCI research closely related to practice.

A successful outcome of a change project such as this, would be to see changes on both a macro and micro level [30], that is in the organizational culture and the formal documentation and routines, as well as on a level of actual practice. Consequently, this case study was not successful since we did not see any changes on macro level during the project. This was partly due to the EA project being prematurely ended. However, we did observe changes on a micro level, within the EA project. The people involved in the project started to ask for our advice and our research data. In their sense making of such concepts as usability and human centeredness, they started to change their vocabulary, using words and descriptions that we would choose. Furthermore, we have observed how they rephrased their work in presentations, using terms such as "work practice" and "user focus".

Our research has confirmed previous research that it is not enough only with guerrilla or project activities, you need management support and an organization that is involved in the specific activities. But we have also found that the guerrilla approach has effect in the small perspective. We therefore argue that UCD guerrilla tactics is a necessary pragmatic contribution. We conclude that a successful implementation of UCD requires three things: 1) explicit widely communicated support in the organization; 2) a local infrastructure with usability competence and well defined UCD methods; 3) guerrilla activities where UCD is tried and exemplified in any opportunity given. 
We argue that one important part of guerrilla tactics is adaptability. Due to the rapidly changing environment, it is important to at all times be prepared to change focus or search for new strategies for UCD work, to do the unexpected (in the sense of making pragmatic unconventional choices) in order to survive. In this, a constant reflexive process is needed: continuous evaluation of the situation in order to adapt to the changing situation. Most of all, to be able to come up with new solutions and be prepared to let go of some prestige, as we did for example when we changed our terminology.

Ultimately, when introducing UCD with UCD we have learnt that it is important to not underestimate the difficulties with multitudes of levels: working both with methods and processes on a general level and with the result from using them. We argue that one cannot be too obvious when it comes to these different levels. Would we do the project again, we would be more aware and clearer in our communication with the organization on what we mean by introducing UCD with UCD and we would try to visualize it in a better way.

Acknowledgements. We would like to thank all the respondents and collaborators within Sweden's military defense organizations. A special thanks to Jan Gulliksen and the anonymous reviewers who have given feedback on earlier versions of this paper.

\section{References}

1. Mao, J., Vredenburg, K., Smith, P., Carey, T.: User-centered design methods in practice: a survey of the state of the art. In: Proceedings of the 2001 Conference of the Centre for Advanced Studies on Collaborative research, Toronto, Canada, p. 12 (2001)

2. Gould, J., Lewis, C.: Designing for usability: key principles and what designers think. Communications of the ACM 28(3), 300-311 (1985)

3. ISO: 13407:1999 Human-centred design processes for interactive systems. International Organization for Standardization Geneva, Switzerland (1999)

4. Gulliksen, J., Göransson, B., Boivie, I., Blomkvist, S., Persson, J., Cajander, Å.: Key principles for user-centred systems design. Behaviour \& Information Technology 22(6), 397-409 (2003)

5. Cajander, Å.: Usability - Who Cares?: The Introduction of User-Centred Systems Design in Organisations. Doctoral Thesis, Acta Universitatis Upsaliensis, Uppsala (2010)

6. Rajanen, M., Iivari, N., Keskitalo, E.: Introducing usability activities into open source software development projects: a participative approach. In: NordiCHI 2012, pp. 683-692. ACM (2012)

7. Mao, J.Y., Vredenburg, K., Smith, P.W., Carey, T.: The state of user-centered design practice. Communications of the ACM 48(3), 105-109 (2005)

8. Lauesen, S.: Usability engineering in industrial practice. In: INTERACT 1997 - IFIP TC13 International Conference on Human-Computer Interaction, Sydney, Australia, pp. 15-22 (1997)

9. Boivie, I.: A Fine Balance: Addressing Usability and Users' Needs in the Development of IT Systems for the Workplace. Doctoral Thesis, Uppsala Unversity, Uppsala: Acta Universitatis Upsaliensis, Sweden (2005)

10. Marti, P., Bannon, L.J.: Exploring User-Centred Design in Practice: Some Caveats. Knowledge, Technology \& Policy 22(1), 7-15 (2009) 
11. Iivari, N.: Representing the User'in software development-a cultural analysis of usability work in the product development context. Interacting with Computers 18(4), 635-664 (2006)

12. Kujala, S., Kauppinen, M., Nakari, P., Rekola, S.: Field Studies in Practice: Making it Happen. In: INTERACT 2003 - IFIP TC13 International Conference on Human-Computer Interaction, pp. 359-366. IOS Press, IFIP (2003)

13. Seffah, A., Gulliksen, J., Desmarais, M.C. (eds.): Human-Centered Software Engineering Integrating Usability in the Software Development Lifecycle. Springer, Dordrecht (2005)

14. Artman, H., Zällh, S.: Finding a way to usability: procurement of a taxi dispatch system. Cognition, Technology \& Work 7(3), 141-155 (2005)

15. Markensten, E., Artman, H.: Procuring a usable system using unemployed personas. In: Third Nordic Conference on Human-Computer Interaction, Tampere, Finland, pp. 13-22 (2004)

16. Markensten, E.: Procuring Usable Systems-An Analysis of a Commercial Procurement Project. In: HCI International Conference, Crete, Greece, pp. 544-548 (2003)

17. Peppard, J.: Managing IT as a Portfolio of Services. European Management Journal 21(4), 467-483 (2003)

18. Nielsen, J.: Guerrilla HCI: Using Discount Usability Engineering to Penetrate the Intimidation Barrier. In: Bias, R.G., Mayhew, D.J. (eds.) Cost-Justifying Usability (Interactive Technologies) (1994)

19. Swartling, A.: The Good Person in Information Systems Development: A Reflexive Investigation of HCI in the Acquisition Process. Doctoral thesis, KTH, Sweden (2008)

20. Rapoport, R.: Three dilemmas in action research. Human Relations 23(6), 499 (1970)

21. McKay, J., Marshall, P.: The dual imperatives of action research. Information Technology and People 14(1), 46-59 (2001)

22. Walsham, G.: Interpretive case studies in IS research: nature and method. European Journal of Information Systems 4(2), 74-81 (1995)

23. Cooper, A.: The inmates are running the asylum. SAMS Publishing, USA (2004)

24. Tohidi, M., Buxton, W., Baecker, R., Sellen, A.: User Sketches: A Quick, Inexpensive, and Effective way to Elicit More Reflective User Feedback. In: NordiCHI 2006 (2006)

25. Cajander, Å., Eriksson, E., Gulliksen, J.: Towards a Usability Coaching Method for Institutionalizing Usability in Organisations. In: Forbrig, P., Paternó, F., Mark Pejtersen, A. (eds.) HCIS 2010. IFIP AICT, vol. 332, pp. 86-97. Springer, Heidelberg (2010)

26. Kurtz, C., Snowden, D.: The new dynamics of strategy: Sense-making in a complex and complicated world. IBM Systems Journal 42(3), 462-483 (2003)

27. Gulliksen, J., Cajander, Å., Sandblad, B., Eriksson, E., Kavathatzopoulos, I.: User-Centred Systems Design as Organizational Change: A Longitudinal Action Research Project to Improve Usability and the Computerized Work Environment in a Public Authority. International Journal of Technology and Human Interaction 5(3), 13-53 (2009)

28. Eriksson, E., Artman, H., Swartling, A.: The secret life of a persona - when the personal becomes private. In: CHI 2013 (accepted, 2013)

29. Walsham, G.: Doing interpretive research. European Journal of Information Systems 15(3), 320-330 (2006)

30. Wiley, N.: The micro-macro problem in social theory. Sociological Theory 6(2), 254-261 (1988) 